\author{
Martin W. Dünser \\ Emir Festic \\ Arjen Dondorp \\ Niranjan Kissoon \\ Tsenddorj Ganbat \\ Arthur Kwizera \\ Rashan Haniffa \\ Tim Baker \\ Marcus J. Schultz \\ Global Intensive Care Working \\ Group of the European Society \\ of Intensive Care Medicine
}

\title{
Recommendations for sepsis management in resource-limited settings
}

\section{in resource-limited settings}

Received: 16 August 2011

Accepted: 4 January 2012

Published online: 14 February 2012

C C Copyright jointly held by Springer and ESICM 2012

Electronic supplementary material

The online version of this article (doi:10.1007/s00134-012-2468-5) contains supplementary material, which is available to authorized users.

\author{
M. W. Dünser ( \\ Department of Anesthesiology, \\ Perioperative and General Critical Care \\ Medicine, Salzburg General Hospital and \\ Paracelsus Private Medical University, \\ Müllner Hauptstrasse 48, 5020 Salzburg, \\ Austria \\ e-mail: M.Duenser@salk.at \\ Tel.: +43-662-448257780

\section{E. Festic} \\ Department of Critical Care Medicine, \\ Mayo Clinic, Jacksonville, FL, USA
}
A. Dondorp
Mahidol Oxford Research Unit, Faculty of Tropical Medicine, Mahidol University, Bangkok, Thailand

\section{N. Kissoon}
Department of Paediatrics and Emergency Medicine, BCCH and UBC Global Child Health, University of British Columbia and the Child and Family Research Institute, Vancouver, Canada

\section{T. Ganbat}

Department of Anesthesiology and Critical Care Medicine, Central State University Hospital, Ulaanbaatar, Mongolia

\section{A. Kwizera}

Department of Anaesthesia, Intensive Care Unit, Makerere University College of Health Sciences, Mulago Hospital, Kampala, Uganda

\section{R. Haniffa}

Department of Anaesthesia and Intensive Care, University College London Hospitals, London, UK

\section{T. Baker}

Department of Physiology and

Pharmacology, Section for Anaesthesia and Intensive Care, Karolinska Institute,

Karolinska University Hospital, Stockholm, Sweden

\section{J. Schultz}

Department of Intensive Care Medicine, Laboratory of Experimental Intensive Care and Anesthesiology, Academic Medical Center, University of Amsterdam, Amsterdam, The Netherlands

Abstract Purpose: To provide
clinicians practicing in resource-lim-
ited settings with a framework to
improve the diagnosis and treatment
of pediatric and adult patients with
sepsis. Methods: The medical liter-
ature on sepsis management was
reviewed. Specific attention was paid
to identify clinical evidence on sepsis
management from resource-limited
settings. Results: Recommendations

are grouped into acute and post-acute interventions. Acute interventions include liberal fluid resuscitation to achieve adequate tissue perfusion, normal heart rate and arterial blood pressure, use of epinephrine or dopamine for inadequate tissue perfusion despite fluid resuscitation, frequent measurement of arterial blood pressure in hemodynamically unstable patients, administration of hydrocortisone or prednisolone to patients requiring catecholamines, oxygen administration to achieve an oxygen saturation $>90 \%$, semi-recumbent and/or lateral position, non-invasive ventilation for increased work of breathing or hypoxemia despite oxygen therapy, timely administration of adequate antimicrobials, thorough clinical investigation for infectious source identification, fluid/tissue sampling and microbiological workup, removal, drainage or debridement of the infectious source. Post-acute interventions include regular reassessment of antimicrobial therapy, administration of antimicrobials for an adequate but not prolonged duration, avoidance of hypoglycemia, pharmacological or mechanical deep vein thrombosis prophylaxis, resumption of oral food intake after resuscitation and regaining of consciousness, careful use of opioids and sedatives, early mobilization, and active weaning of invasive support. Specific considerations for malaria, 
puerperal sepsis and HIV/AIDS patients with sepsis are included. Conclusion: Only scarce evidence exists for the management of pediatric and adult sepsis in resourcelimited settings. The presented recommendations may help to improve sepsis management in middle- and low-income countries.

Keywords Sepsis - Intensive care · Resource-limited settings .
Middle-income countries .

Low-income countries .

Recommendations · Management

\section{Introduction}

Infection and sepsis are among the leading causes of death worldwide. The annual burden of sepsis in highincome countries is estimated to approach 2.8 million cases with a mortality of $\sim 40 \%$ [1]. Despite these figures from industrialized countries, the largest part of the global sepsis burden occurs in middle- and low-income countries. Ninety percent of the worldwide deaths from pneumonia, meningitis or other infections occur in less developed countries [2]. Around $70 \%$ of the 9 million global deaths in neonates and infants are attributable to sepsis, with the majority of cases occurring in Asia and sub-Saharan Africa [3]. A high incidence of bacterial, parasitic and HIV infection combined with low hygienic standards and vaccination rates, widespread malnutrition and lack of resources, explain the disproportionally high morbidity and mortality from sepsis in these countries $[4,5]$.

In 2004 and 2008, the Surviving Sepsis Campaign released guidelines for severe sepsis and septic shock management [6, 7]. Implementation of these guidelines together with timely administration of essential therapies (e.g., fluid resuscitation, antibiotics, source control measures) improved management and outcome [8,9]. Similar initiatives have been undertaken in children resulting in comparable improvements in outcome [10,11]. Despite their benefits, the Surviving Sepsis Campaign and the American College of Critical Care Medicine pediatric guidelines cannot be implemented in most middle- or low-income countries due to lacking resources [12-15]. This leaves those clinicians caring for the majority of sepsis patients worldwide without standardized and adoptable guidance for sepsis care.

The purpose of these recommendations is to provide clinicians practicing in resource-limited settings with a framework to improve the management of pediatric and adult septic patients. The recommendations are specifically based on resources affordable and commonly available in middle- and low-income countries and systematically weigh the available scientific evidence for its applicability in resource-limited settings. They are not meant to replace the Surviving Sepsis Campaign $[6,7]$ or American College of Critical Care Medicine pediatric guidelines $[10,11]$ but can be considered if the latter are impossible to implement due to resource constraints.

\section{Methods}

These recommendations were developed by the Global Intensive Care working group of the European Society of Intensive Care Medicine and the World Federation of Pediatric Intensive and Critical Care Societies. The working group consists of critical care physicians and nurses from high-, middle- and low-income countries aiming to improve intensive care in resource-limited areas. Their members have extensive experience in caring for critically ill patients in resource-limited settings. No external funding was used. None of the authors had a financial conflict of interest in regards to drugs or techniques discussed in the manuscript or received honoraria for any role while establishing the recommendations.

Plans and methods to develop the recommendations were conceptualized in summer 2010. The group met at the 23rd ESICM Congress in Barcelona/Spain, and the 31st ISICEM in Brussels/Belgium. In between, face-toface meetings, teleconferences and electronic-based discussions among group members were held to improve the recommendations. Any disagreement was resolved by further discussion and consensus, whenever possible. Voting results of the expert panel on individual recommendations are presented in the Electronic Supplementary Material.

To identify the contemporary scientific evidence for sepsis management, a structured literature review was conducted using pre-defined terms (see Electronic Supplementary Material for further details on the search process). Furthermore, reference lists of identified articles, the latest sepsis guidelines, textbooks and personal libraries were reviewed. Specific attention was paid to identify clinical evidence on sepsis management originating from resource-limited settings. Based on survey data on the availability of resources to implement the Surviving Sepsis Campaign guidelines and American College of Critical Care Medicine pediatric guidelines in middle- and low-income countries [12-15], scientific evidence was adjusted to resource-limited settings. In addition, expert opinion and clinical experience of the authors in providing sepsis care in middle- and lowincome countries was considered. The level of scientific evidence (LoE) of each recommendation was classified as high (LoE: A; supported by the results of randomized, controlled trials or meta-analyses), moderate (LoE: B; supported by the results of low-quality randomized 
controlled trials or high-quality observational studies), low (LoE: C; supported by the results of observational studies) or very low (LoE: D; supported by the results of case series or the opinion of experts). Since extrapolation of evidence from well-resourced to resource-limited countries is problematic given fundamental differences in sepsis epidemiology [2, 4], the educational level of health care providers $[15,16]$, health care facilities and resources [12-15], the level of evidence attributed to some recommendations differs from recommendations published by others $[6,7,10]$.

\section{Recognizing the septic patient}

Recognizing the patient with sepsis is an essential step for effective treatment. Given the widespread lack of facilities to diagnose sepsis according to international definitions in resource-limited settings, modified definitions of sepsis, severe sepsis and septic shock, which can be applied also with limited resources, are summarized in Table 1. More details on how to recognize the patient with sepsis in resource-limited settings are given in the Electronic Supplementary Material.

\section{Treating the septic patient}

General considerations

General considerations regarding the treatment of patients with sepsis are summarized in Table 2. More details are presented in the Electronic Supplementary Material.

Acute interventions

Acute interventions (Table 3) refer to treatments recommended to be administered without delay. Although acute interventions are presented and suggested in this manuscript in a certain order (Fig. 1), some interventions could and should be performed simultaneously, depending on the condition of the patient.

\section{Circulation}

1. Use adequate tissue perfusion as the principal endpoint of resuscitation (LoE: A). In addition, target a systolic arterial blood pressure $>90 \mathrm{mmHg}$ in adults, as well as normal heart rate and arterial blood pressure in children (LoE: D).

Background Given that tissue hypoperfusion is a key factor contributing to sepsis-associated organ failure [17], one principal goal of resuscitation is to promptly restore tissue perfusion $[6,7]$. Although adequate tissue perfusion is often associated with a systolic arterial blood pressure $>90 \mathrm{mmHg}$, some patients may restore tissue perfusion with lower arterial pressures. On the other hand, achievement of a normal arterial blood pressure is not necessarily associated with adequate tissue perfusion [18]. Therefore, arterial blood pressure alone is not a reliable endpoint for assessing adequacy of tissue perfusion. Although no clinical parameter exists to directly assess adequacy of tissue perfusion, clinical variables presented in Table 4 may be used [19]. Clinical signs of dehydration (e.g., dry mucous membranes, skin tenting) are rare in acute sepsis and should make the clinician consider a subacute or chronic disease process with superimposed infection.

2. In patients with tissue hypoperfusion, infuse fluids aggressively and continue liberal infusions for 24-48 h (LoE: C). More than $4 \mathrm{~L}$ during the first $24 \mathrm{~h}$ may be required to adequately resuscitate the adult septic patient.

Background Despite the development of interstitial edema, hypovolemia arising from true fluid loss or capillary leakage with interstitial edema formation is a main cause of tissue hypoperfusion in sepsis [20]. Fluid therapy increases systemic blood flow and oxygen delivery [21]. Aggressive fluid resuscitation reduced mortality in patients with typhoid ileal perforation in rural Africa [22]. In Ugandan patients with Gram negative bacteremia, mortality was decreased in patients receiving $>1 \mathrm{~L}$ of fluid compared to those receiving less or no fluids [23]. Children with septic shock receiving $<20 \mathrm{~mL} / \mathrm{kg}$ of fluids had twice as high mortality compared to children receiving $>40 \mathrm{~mL} / \mathrm{kg}$ of fluids during the first hour [24]. Fluid resuscitation is of particular importance in children with the Dengue shock syndrome, a clinical scenario characterized by vascular leakage and hypovolemia [25, 26].

A recent study by Maitland et al. [27] reported increased mortality in African children (median age 24 months) with sepsis who received fluid boluses in addition to maintenance fluids $(2.5-4 \mathrm{~mL} / \mathrm{kg} / \mathrm{h})$. Harmful effects of fluid boluses were mainly observed in children with compensated shock and profound anemia. More than half of the children had malaria, a state where microcirculatory dysfunction is common due to sequestration of parasitized erythrocytes rather than frank hypovolemia. Widespread lack of intensive care facilities among study centers may have contributed to harmful effects of aggressive fluid loading.

Based on these data, patients with sepsis and tissue hypoperfusion appear to benefit from a rapid bolus of intravenous crystalloid solution of at least $20 \mathrm{~mL} / \mathrm{kg}$. Further fluid resuscitation should be guided by the 
Table 1 Definition of infection and sepsis syndromes

Suggested sepsis diagnosis with limited resources

Proven or highly suspected infection plus presence of $\geq 2$ of the following conditions:

Sepsis

Heart rate $>90 \mathrm{bpm}$

Respiratory rate $>20 \mathrm{bpm}$

Temperature $<36$ or $>38^{\circ} \mathrm{C}$

Malaise and/or apathy

Severe Sepsis-induced tissue hypoperfusion or organ dysfunction

sepsis Tissue hypoperfusion

Decreased capillary refill or skin mottling

Peripheral cyanosis

Arterial hypotension

Systolic arterial blood pressure $<90 \mathrm{mmHg}$ or a systolic arterial blood pressure decrease $>40 \mathrm{mmHg}$

Pulmonary dysfunction

$\mathrm{SpO}_{2}<90 \%$ with or without oxygen

Central cyanosis

Signs of respiratory distress (e.g., dyspnea, wheezing, crepitations, unability to talk sentences)

Renal dysfunction

Acute oliguria (urine output $<0.5 \mathrm{~mL} / \mathrm{kg} / \mathrm{h}$ or $45 \mathrm{~mL} / \mathrm{h}$ for at least $2 \mathrm{~h}$ despite adequate fluid resuscitation)

Hepatic dysfunction

Jaundice

Coagulation dysfunction

Petechiae or ecchymoses

Bleeding/oozing from puncture sites

Gastrointestinal dysfunction

Ileus (absent bowel sounds)

Septic shock Sepsis-induced arterial hypotension despite adequate fluid resuscitation (note that patients on inotropics or vasopressors may not be hypotensive despite of presence of shock) and signs of tissue hypoperfusion
Sepsis diagnosis according to international consensus (22, 23)

Proven or highly suspected infection plus presence of $\geq 2$ of the following conditions:

Heart rate $>90 \mathrm{bpm}$

Respiratory rate $>20$ bpm or $\mathrm{PaCO}_{2}<32 \mathrm{mmHg}$

Temperature $<36$ or $>38^{\circ} \mathrm{C}$

WBC $<4$ or $12 \mathrm{~g} / \mathrm{L}$ or $>10 \%$ immature forms

Sepsis-induced tissue hypoperfusion or organ dysfunction Tissue hypoperfusion

Decreased capillary refill or skin mottling

Hyperlactatemia $(>1 \mathrm{mmol} / \mathrm{L})$

Arterial hypotension

Systolic arterial blood pressure $<90 \mathrm{mmHg}$; mean arterial blood pressure $<70 \mathrm{mmHg}$; or a systolic arterial blood pressure decrease $>40 \mathrm{mmHg}$

Pulmonary dysfunction

$\mathrm{PaO}_{2} / \mathrm{FiO}_{2}<300$

Renal dysfunction

Acute oliguria (urine output $<0.5 \mathrm{~mL} / \mathrm{kg} / \mathrm{h}$ or $45 \mathrm{~mL} / \mathrm{h}$ for at least $2 \mathrm{~h}$ despite adequate fluid resuscitation)

Creati nine increase $>0.5 \mathrm{mg} / \mathrm{dL}$ or $44.2 \mu \mathrm{mol} / \mathrm{L}$

Hepatic dysfunction

Hyperbilirubinemia (plasma total bilirubin $>4 \mathrm{mg} / \mathrm{dL}$ or $70 \mu \mathrm{mol} / \mathrm{L}$

Coagulation dysfunction

Thrombocytopenia (platelet count, $<100,000 / \mu \mathrm{L}$ )

Coagulation abnormalities (INR $>1.5$ or a PTT $>60 \mathrm{~s}$ )

Gastrointestinal dysfunction

Ileus (absent bowel sounds)

Sepsis-induced arterial hypotension despite adequate fluid resuscitation (note that patients on inotropics or

vasopressors may not be hypotensive despite of presence of shock) and signs of tissue hypoperfusion
$\mathrm{PaCO}_{2}$ partial arterial carbon dioxide tension, $W B C$ white blood cell count, $\mathrm{SpO}_{2}$ plethysmographic oxygen saturation, $\mathrm{PaO}_{2} / \mathrm{FiO}_{2}$ partial arterial oxygen tension/fractional inspiratory oxygen concentration quotient, INR international normalized ratio, PTT partial thromboplastin time response to fluid loading. A positive response to fluid loading can be considered as one of the following: $>10 \%$ increase of systolic/mean arterial blood pressure, $>10 \%$ reduction of heart rate, and/or improvement of mental state, peripheral perfusion and/or urine output. Some adult patients may require several liters of fluids during the first $24-48 \mathrm{~h}$ to achieve this goal. Likewise, fluid amounts as high as $110 \mathrm{~mL} / \mathrm{kg}$ may be required in children with septic shock during early resuscitation [28]. In children with profound anemia and severe sepsis, particularly due to malaria, fluid boluses must only be administered cautiously, and blood transfusion should be considered instead [27].

Fluid resuscitation should be stopped or interrupted when no improvement of tissue perfusion occurs in response to volume loading. Development of crepitations in adults plus hepatomegaly in children indicate fluid overload or impaired cardiac function. Since aggressive fluid resuscitation can lead to respiratory impairment, additional fluid resuscitation following the initial fluid boluses should be performed carefully if no mechanical ventilator is available. In such a scenario, it may be necessary to balance adequate pulmonary gas exchange against optimum intravascular filling. However, this is an infrequent conundrum within the first $6 \mathrm{~h}$.

Fluid administration in septic patients should occur intravenously even if access needs to be attained by surgical cut-down or central venous cannulation. Alternatively, an intra-osseous access may be used. An intraosseous cannula should only be used if running freely and for $<24 \mathrm{~h}$. Although oral rehydration is efficient to treat dehydration [29], no data on the efficacy and safety of oral 
Table 2 General considerations for sepsis care

Timing

Patient monitoring

Multidisciplinary care

Data documentation

Emergency drugs and equipment

Patient transfer

Estimating prognosis and Treatment limitation

Quality control
Diagnose sepsis as early as possible (LoE: D)

Initiate sepsis treatment as early as possible (LoE: B). Antimicrobials should be given within $1 \mathrm{~h}$ of recognizing sepsis (LoE: C). Hemodynamic endpoints should be achieved within $6 \mathrm{~h}$ of recognizing sepsis (LoE: C)

Wash hands before and after each patient contact and whenever contaminated (LoE: B). Prefer alcohol rubs, otherwise use running water and soap

Use sterile barrier precautions when performing invasive procedures or surgical interventions (LoE: A)

Never leave the septic patient alone. Ensure continuous observation (LoE: D)

Perform clinical examinations several times per day (LoE: D)

Whenever available use a continuous patient monitor and set meaningful alarm limits (1D). Alarms for children should be set at age appropriate ranges (LoE: D)

Whenever applicable, seek consultation from experienced health care workers of other medical specialties (LoE: D)

Keep a patient record and document vital signs at meaningful intervals (LoE: D)

If the patient deteriorates or fails to improve look for the cause and seek medical review (LoE: D)

Convey essential information to all team members involved in the care of the septic patient (LoE: C)

Keep an emergency supply of drugs and equipment on the ward that is available $24 \mathrm{~h}$ /day and is checked and replenished daily (LoE: D)

Transfer of septi c patients to hospitals with more resources and/or medical expertise may save lives. However, the risks must always be critically weighed against benefits (LoE: D)

Whenever possible transfer should be attended by a physician or other experienced medical personnel (LoE: D)

For each patient, critically assess the prognosis and extent of treatment (LoE: D)

Limit treatment in adult patients with grave prognosis (LoE: D). Whenever possible make decisions together with other colleagues and compassionately communicate it to the patient and family

Whenever possible and compatible with local culture, perform autopsies in patients who died from sepsis. Communicate autopsy results to all team members and critically discuss points that could have been done better (LoE: D)

Identify local strengths and weaknesses in sepsis management by documenting key aspects of sepsis care and outcome (LoE: D)

$L o E$ level of evidence

Table 3 Acute interventions to treat septic patients with limited resources

Circulation Use adequate tissue perfusion as the principal endpoint of resuscitation (LoE: A). In addition, target a systolic arterial blood pressure $>90 \mathrm{mmHg}$ in adults, as well as normal heart rate and arterial blood pressure in children (LoE: 2D)

In patients with tissue hypoperfusion, infuse fluids aggressively and continue liberal infusions for $24-48 \mathrm{~h}$ (LoE: C). More than $4 \mathrm{~L}$ during the first $24 \mathrm{~h}$ may be required to adequately resuscitate the adult septic patient

Use crystalloids and/or colloids for fluid resuscitation (LoE: B). When available, use colloid solutions for fluid resuscitation in children with severe Dengue shock syndrome (LoE: B)

Use dopamine or epinephrine (adrenaline) in patients with persistent tissue hypoperfusion despite liberal fluid resuscitation (LoE: C)

In patients requiring dopamine or epinephrine (adrenaline) measure arterial blood pressure and heart rate frequently (LoE: D)

Administer intravenous hydrocortisone (up to $300 \mathrm{mg} /$ day) or prednisolone (up to $75 \mathrm{mg} /$ day) to adult patients requiring escalating dosages of epinephrine (adrenaline) or dopamine (LoE: B). Consider the use of equivalent hydrocortisone or prednisolone doses in children with severe shock (LoE: C)

Ventilation Apply oxygen to achieve an oxygen saturation $>90 \%$ (LoE: B). If no pulse oximeter is available administer oxygen empirically in patients with severe sepsis or septic shock (LoE: C)

Place patients in a semi-recumbent position (head of the bed raised to 30-45 ${ }^{\circ}$ (LoE: C)

Unconscious patients should be placed in the lateral position. The patient's airway should be kept clear (LoE: D)

If available and medical staff is adequately trained, use non-invasive ventilation in patients with dyspnea and/or persistent hypoxemia despite oxygen therapy (LoE: C)

Antimicrobial Initiate sepsis treatment as early as possible (LoE: B). Antimicrobials should be given within $1 \mathrm{~h}$ of recognizing therapy sepsis (LoE: C)

Administer intravenous antimicrobials at adequate dosages and with a high likelihood to be active against the suspected bacterial pathogens (LoE: C)

Diagnosis Perform a detailed patient history and thorough clinical examination to identify the source of infection (LoE: D). Use imaging techniques when available (LoE: D)

Whenever possible and without harm to the patient, sample fluid or tissue from the site of infection (LoE: C)

Examine the sampled fluid or tissue by Gram stain, culture and whenever possible by antibiogram (LoE: C)

Source control

Whenever possible drain or debride the source of infection (LoE: C)

Remove any foreign body or device that may potentially be the source of infection (LoE: C)

$L o E$ level of evidence 


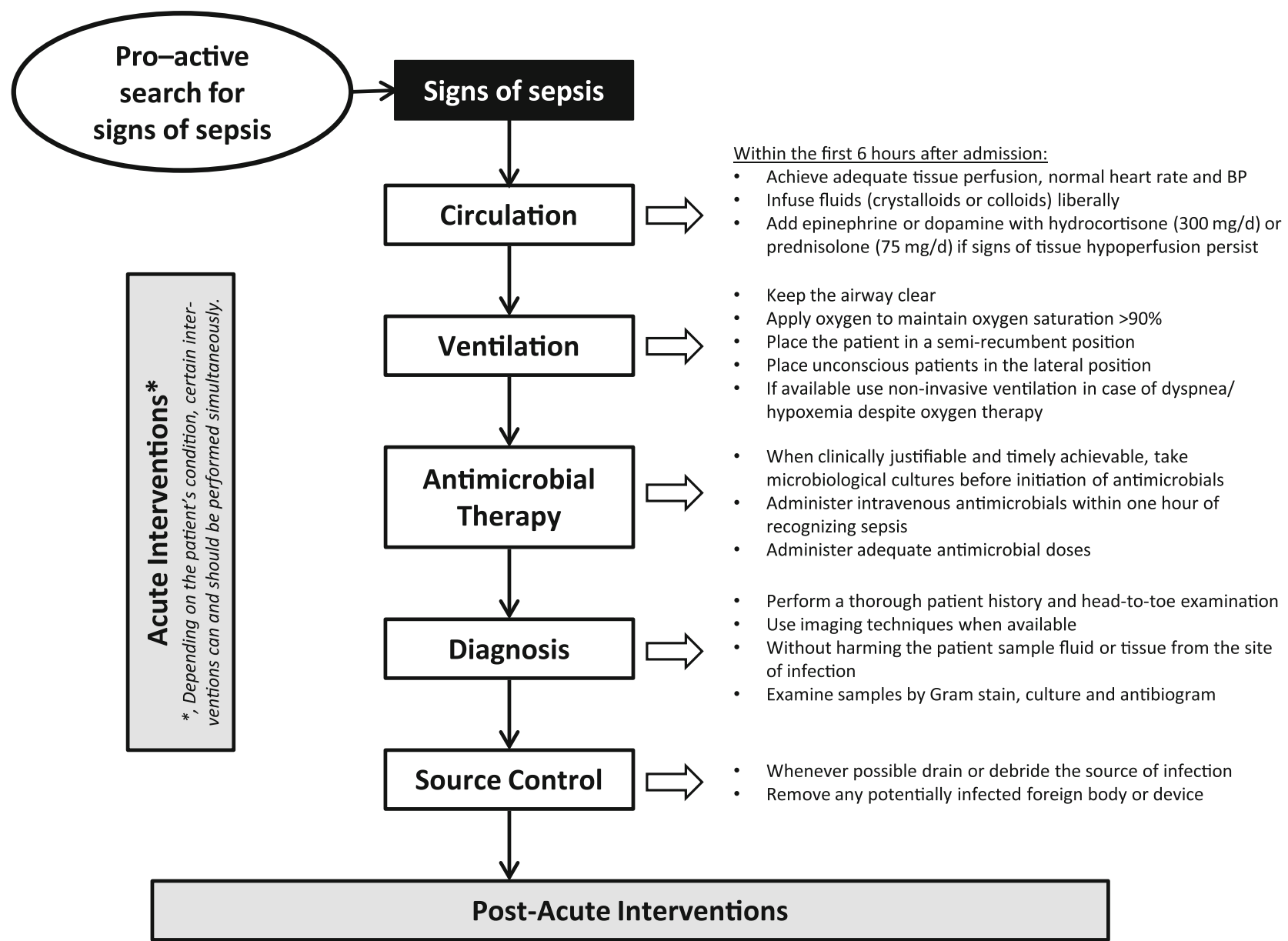

Antimicrobial Therapy:

- Reassess the effectiveness of antimicrobial therapy regularly

- Administer antimicrobials for an adequate but not prolonged time

Glucose Control:

- Whenever possible check blood glucose levels

- Maintain blood glucose $>70 \mathrm{mg} / \mathrm{dL}(4 \mathrm{mmol} / \mathrm{L})$

Deep Vein Thrombosis:

- Use prophylactic heparin or apply elastic bandages on both legs

- No deep vein thrombosis prophylaxis in pre-pubertal children

Enteral Nutrition and Stress Ulcer Prophylaxis:

- Allow the patient to eat and dring small amounts once she/he is fully resuscitated and awake

Sedation and Pain Relief:

- Use opioids to relief pain but be cautious in unstable patients

- Only sedate the agitated and uncooperative patient

- Encourage mobilization as soon as the patient is stable

Wean Invasive Support:

- Remember that every therapy and intervention has the potential to harm the patient

- As soon as the patient is improving, try to actively wean the extent of invasive support

DO NOT use hypotonic fluids for fluid resuscitation; DO NOT use fluid balance as a guide for fluid therapy; DO NOT use high dose steroids; DO NOT use muscle relaxants (except for endotracheal intubation); DO NOT use succinylcholine in immbolized patients; DO NOT use furosemide unless hypervolemia, hyperkalemia and/or acidosis are present; DO NOT use dopamine for renal indications; DO NOT use sodium bicarbonate; DO NOT use non-steroidal anti-inflammatory drugs; DO NOT use sodium bicarbonate; DO NOT restrict oxygen; DO NOT diagnose "fever of unknown origin“; DO NOT use insulin if blood glucose cannot be measured regularly.

Fig. 1 Flowchart and summary of recommendations 
Table 4 Clinical indicators of adequate tissue hypoperfusion

Normal capillary refill time ${ }^{\mathrm{a}}$

Absence of skin mottling

Warm and dry extremities

Well felt peripheral pulses (e.g., radial or dorsalis pedis pulses)

Return to baseline mental status before sepsis onset

Urine output $>0.5$ (adults) or 1 (children) $\mathrm{mL} / \mathrm{kg} / \mathrm{hour}^{\mathrm{b}}$

a Age dependent: children and adults ( $<65$ years), $<2-3 \mathrm{~s}$; elderly patients $(>65$ years $)<4.5 \mathrm{~s}$

b Unless elevated creatinine plasma levels or sign of established renal failure

rehydration in septic patients with tissue hypoperfusion exist. Considering a relevant aspiration risk, oral rehydration should be avoided in septic shock patients.

3. Use crystalloids and/or colloids for fluid resuscitation (LoE: B). When available, use colloid solutions in children with severe Dengue shock syndrome (LoE: B).

Background There are no data supporting the superiority of colloid over crystalloid solutions for resuscitation of adults or children with bacterial sepsis [28, 30, 31]. In most situations, adequacy of fluid resuscitation is more relevant than the type of fluid infused. Considering high costs [32], the risk of allergies [33] and potential renal and coagulatory side effects [34] of colloids, crystalloid solutions appear more suitable in resource-limited settings. However, colloids may bear potential benefits in children with severe Dengue shock syndrome (pulse pressure $\leq 10 \mathrm{mmHg}$ ) [25]. In moderate Dengue shock syndrome (pulse pressure $>10$ and $\leq 20 \mathrm{mmHg}$ ) colloid and crystalloid solutions lead to similar outcomes. Since moderate Dengue shock syndrome is more common than severe, crystalloids remain the first-line fluid in the majority of cases $[25,31]$.

4. Use dopamine or epinephrine (adrenaline) in patients with persistent tissue hypoperfusion despite liberal fluid resuscitation (LoE: C).

Background If fluid resuscitation cannot restore tissue perfusion, the use of dopamine or epinephrine (adrenaline) should be considered. While cool extremities, extended neck veins, crepitations or crackles, a third or fourth heart sound, and/or a positive hepato-jugular reflux characterize the patient with impaired heart function, patients with excessive peripheral vasodilation typically present with warm extremities, oliguria and impaired mental state. In many cases, however, it is difficult to differentiate between the two states without measuring cardiac output. Arrhythmogenic and obstructive causes of fluid-resistant tissue hypoperfusion (e.g., pneumothorax, pericardial tamponade, abdominal compartment syndrome) must be excluded.
Studies suggest that neither dopamine nor epinephrine is inferior to a balanced infusion of norepinephrine (noradrenaline) and dobutamine with respect to septic shock outcome [35-37]. Considering frequent aggravation of lactic acidosis during epinephrine infusion [38], norepinephrine should, whenever available, be preferred over epinephrine. Since all catecholamines typically exert dose-dependent adverse side effects, doses should be kept at a minimum. Although dopamine-refractory shock may be reversed with epinephrine or norepinephrine infusion in children [39], combined use of dopamine and epinephrine is discouraged.

Preferentially, dopamine or epinephrine is infused through a central venous catheter. If central venous catheters are unavailable or the medical staff has insufficient experience handling them [40], a peripheral venous cannula, placed in a large bore vein, or an intra-osseous cannula can be used. It is important to frequently check the site of infusion for signs of drug extravasation, since substantial skin necrosis may occur [41]. Dopamine and epinephrine should be administered continuously. When pumps are unavailable or power cuts frequently occur, dopamine (e.g., $250 \mathrm{mg}$ ) or epinephrine (e.g., 5-10 mg) can be diluted in $500 \mathrm{~mL}$ of crystalloid solution and infused using a drop regulator or micro-infusion set. Dosing should occur based on the clinical response.

5. In patients requiring dopamine or epinephrine (adrenaline) measure arterial blood pressure and heart rate frequently (LoE: D).

Background In children and adults requiring dopamine or epinephrine (adrenaline), blood pressure should be measured frequently $[6,7,11]$. The invasive technique is rarely available in resource-limited settings and requires specific training. Alternatively, blood pressure can be measured non-invasively. Specifically in children, adequately sized cuffs must be used to ensure accurate readings. Intervals for non-invasive blood pressure measurements should be set at $5-15 \mathrm{~min}$ as long as epinephrine or dopamine is infused.

6. Administer intravenous hydrocortisone (up to $300 \mathrm{mg}$ / day) or prednisolone (up to $75 \mathrm{mg} /$ day) to adult patients requiring escalating dosages of epinephrine (adrenaline) or dopamine (LoE: B). Consider the use of equivalent hydrocortisone or prednisolone doses in children with severe shock (LoE: C).

Background Relative adrenal insufficiency with inadequately low plasma cortisol levels is frequent in septic shock [42]. If hydrocortisone is administered to adults requiring escalating catecholamine doses in high-income settings, shock duration and mortality are reduced [42, 43]. An Indian randomized pilot study suggested a trend towards earlier shock reversal and less inotrope use when 
hydrocortisone $(5 \mathrm{mg} / \mathrm{kg} /$ day in four divided doses followed by half the dose for a total of 7 days) was administered to children with septic shock [44]. Until more data are available, use of hydrocortisone must be considered a rescue therapy in pediatric septic shock. Daily corticosteroid dosages must not exceed equivalent doses of $300 \mathrm{mg}$ hydrocortisone or $75 \mathrm{mg}$ prednisolone, since higher doses may predispose for infections [45]. Corticosteroids should not be administered to patients not requiring catecholamines unless they are on chronic corticosteroid therapy. When epinephrine or dopamine can be withdrawn, corticosteroids should be tapered off (over days) to avoid rebound hypotension [42].

\section{Ventilation}

1. Apply oxygen to achieve an oxygen saturation $>90 \%$ (LoE: B). If no pulse oximeter is available administer oxygen empirically in patients with severe sepsis or septic shock (LoE: D).

Background Apart from tissue hypoperfusion, organ dysfunction associated with sepsis arises from hypoxemia [46], which is highly prevalent in resource-limited settings [47]. Clinical signs (e.g., cyanosis) are not reliable, particularly in patients with dark complexion. Clinical signs of respiratory distress (dyspnea, increased work of breathing) reflect changes in respiratory mechanics and may not be reliable gauges of hypoxemia. Therefore, it is essential to monitor septic patients with a pulse oximeter $[48,49]$. Patients presenting with hypoxemia should receive oxygen to achieve an oxygen saturation $>90 \%$. In Papua New Guinea, installation of hospital wide oxygen systems facilitated oxygen therapy for hypoxemic children with pneumonia and reduced the risk of death [50]. If no pulse oximeter is available, oxygen should empirically be administered to all septic patients (see Electronic Supplementary Material for technical details).

2. Place patients in a semi-recumbent position (head of the bed raised to $30-45^{\circ}$ ) (LoE: C).

Background Unless hemodynamically unstable, septic patients should be placed in a semi-recumbent position (head of the bed raised to $30-45^{\circ}$ ). Semi-recumbency reduces the risk of tracheal aspiration and hospitalacquired pneumonia, particularly when mental state is impaired or enteral nutrition administered [51, 52].

3. Unconscious patients should be placed in the lateral position. The patient's airway should be kept clear (LoE: C).

Background Unconscious patients and subjects who cannot keep their airway open for other reasons should be placed in the lateral position. In addition, an oro- or nasopharyngeal airway can be inserted if the lateral position alone cannot maintain airway patency. Inability to clear the airway is associated with a high risk for aspiration of saliva or regurgitated gastric contents. Oral hygiene (tooth brushing and cleansing with an oral antiseptic at least twice daily), repetitive suctioning of oropharyngeal secretions and placement in the semirecumbent position (also the lateral position) can prevent pneumonia [53].

4. If available and medical staff is adequately trained, use non-invasive ventilation in patients with dyspnea and/ or persistent hypoxemia despite oxygen therapy (LoE: C).

Background Sepsis may lead to deterioration of lung function. In severe cases, respiratory insufficiency may not be sufficiently treated by oxygen alone, even when administered at high flow rates. Wherever available and when medical staff is adequately trained, mechanical ventilation should be instituted early in patients with increased work of breathing and/or persistent hypoxemia despite oxygen therapy. In many resource-limited settings, non-invasive mechanical ventilation (administration of ventilatory support through a mask instead of an endotracheal tube or tracheostoma) appears to be the ventilation technique of choice [54]. Non-invasive ventilation has been applied with good success in patients with acute respiratory failure in Pakistan [55]. Data from India reported that non-invasive intermittent positive pressure ventilation decreased the need for endotracheal intubation in acute respiratory failure of diverse origin [56]. Nasal continuous positive airway pressure improved the management of respiratory insufficient children with Dengue hemorrhagic fever in Southeast Asia [57]. Despite these positive reports, studies performed in high-income settings demonstrate that not all patients can successfully be managed with noninvasive ventilation [54]. This is specifically true for septic patients with impaired consciousness, severe respiratory or cardiovascular failure. Particularly young children may not tolerate non-invasive ventilation. Furthermore, airway anatomy (large tongue, short neck) combined with the need for lower tidal volumes makes non-invasive ventilation in children difficult [58].

If equipment is available and medical staff adequately trained, mechanical ventilation may be delivered via an endotracheal tube. When doing so an adequate level of positive end-expiratory pressure with tidal volumes of $6 \mathrm{~mL} / \mathrm{kg}$ ideal body weight should be set $[59,60]$. Furthermore, peak (pressure control ventilation mode) or plateau (volume control ventilation mode) pressures should not exceed $30 \mathrm{cmH}_{2} \mathrm{O}$ [61]. Spontaneous breathing modes are equally preferred in intubated patients [62]. If mechanical ventilators are unavailable, anesthetic circuits or machines may be used to ventilate a patient with respiratory distress or during the postoperative period. 


\section{Antimicrobial therapy}

1. Initiate sepsis treatment as early as possible (LoE: B). Antimicrobials should be given within $1 \mathrm{~h}$ of recognizing sepsis (LoE: $\mathrm{C}$ ).

Background Robust evidence indicates that timely diagnosis of sepsis and rapid initiation of treatment reduces morbidity and mortality both in children and adults [63-68]. In a high-income country, each hour of delay in antibiotic administration was associated with an average $7.6 \%$ decrease in survival of septic shock [66]. Similarly, in a predominantly HIV-infected septic patient population in Uganda, any delay in the administration of adequate antibiotics increased all cause and attributable mortality [23]. Likewise, pre-referral administration of rectal artesunate reduced death in severe malaria in rural Asia and Africa [69].

2. Administer intravenous antimicrobials at adequate dosages and with a high likelihood to be active against the suspected bacterial pathogens (LoE: C).

Background Intravenous antimicrobial therapy is one of the key treatments in septic patients. If intravenous access cannot be promptly attained in children, first antimicrobial dosages may be administered intra-muscularly or by the oral or rectal route. Two factors critically determine the benefit of antimicrobial therapy both in resource-rich [66-68] and resource-limited settings [22]: timing and adequacy. Since the causative pathogen cannot be identified immediately, antimicrobial therapy must be started empirically. To ensure that empirical antimicrobial therapy is active against the causative microorganisms, it is vital to account for the likely pathogen spectrum. In middle- and low-income settings, this is particularly challenging since the range of infectious diseases and causative microorganisms is broad, including bacterial, viral, fungal and parasitic pathogens [23]. Further difficulties arise from frequent antimicrobial resistance [70], common preceeding self-medication with over-the-counter antibiotics [71, 72] and the limited availability of potent intravenous antimicrobials [12-15]. Considerable regional heterogeneities in these aspects make recommendation of empirical antimicrobial strategies difficult. In a multicenter study performed in middle- and lowincome countries, chloramphenicol was superior to injectable ampicillin plus gentamicin in the treatment of community-acquired severe pneumonia in children aged 2-59 months [73]. To optimize chances of appropriate empirical antimicrobial therapy, empiric antimicrobial therapy should be adjusted to local infectious disease patterns including HIV/AIDS prevalence, pathogen spectrum and antimicrobial resistance.

Adequate dosing is another important aspect of antimicrobial therapy. Considering the high risk of death associated with sepsis, antimicrobial drugs need to be administered at maximum recommended dosages during the initial phase [74]. This is of particular importance if antimicrobials of unclear quality (e.g., counterfeit or expired drugs) are used. Following the acute phase, many antibiotics require dose adjustments to renal or hepatic function. To achieve optimum bioavailability, the intravenous route is preferred. When the patient improves, antimicrobials may be administered orally provided that intestinal absorption is maintained.

\section{Diagnosis}

1. Perform a detailed patient history and thorough clinical examination to identify the source of infection (LoE: D). Use imaging techniques when available (LoE: D).

Background Following first resuscitation steps and initiation of empirical antimicrobial therapy, it is critical to identify the source of infection. A thorough patient history and clinical investigation are essential to do so. Although imaging techniques (e.g., X-ray, ultrasound) may be used to answer specific diagnostic questions, nothing can replace a thorough medical history and systematic head-to-toe examination.

2. Whenever possible and without harm to the patient, sample fluid or tissue from the site of infection (LoE: C).

Background Microbiological identification of the causative microorganism of sepsis is useful to confirm presence the diagnosis and allows for targeted antimicrobial therapy. For microbiological cultures, blood, fluid or tissue from the suspected site of infection needs to be sampled in a sterile fashion [75]. Whenever clinically justifiable and timely achievable this should be done before initiation of empirical antimicrobial therapy to maximize the sensitivity of microbiological cultures. If microbiological cultures are unavailable, it may still be rational to collect samples for visual or microscopic analysis.

3. Examine the sampled fluid or tissue by Gram stain, culture and whenever possible for antibiotic susceptibility (LoE: C).

Background After samples have been obtained, transport to the microbiological laboratory should take place as fast as possible. Gram staining and microscopic examination should be performed whenever applicable. Also in resource-limited areas, microbiological cultures remain the gold standard to cultivate microbes. When microorganisms grow, susceptibility to locally available antibiotics should be assessed allowing for targeted antimicrobial therapy. Where parasitic infections are endemic 
or suspected specific laboratory tests should be used (e.g., thick smear analysis for diagnosis of malaria). Rapid communication of positive microbiological test results to the clinician in charge is imperative.

\section{Source control}

1. Whenever possible drain or debride the source of infection (LoE: C).

Background Along with timely and adequate antimicrobial therapy, source control is the only causative therapy of sepsis. As soon as basic resuscitation measures and empiric anti-infective therapy have been instituted, source control measures must be prioritized. Source control measures should be timed depending on several factors such as the patient's condition, surgical expertise and resource availability. In invasive Staphylococcus aureus infection, source control reduced mortality in a provincial hospital in northeast Thailand [76]. Typical infectious sources requiring emergent source control measures are abscesses (except for pulmonary abscesses), necrotizing soft tissue and wound infections, gastrointestinal perforation, cholangitis, obstructive urinary tract infection, and any deep space infection such as pleural empyema or septic arthritis. Depending on local availability of experts and resources, the least invasive technique should be chosen (e.g., percutaneous/endoscopic instead of surgical abscess drainage). Not all infectious sources are amenable to surgical source control (e.g., pneumonia, meningitis). In these patients, timing and adequacy of antimicrobial therapy remain the key component of sepsis care.

2. Remove any foreign body or device that may potentially be the source of infection (LoE: C).

Background Device-related infections are particularly frequent in intensive care units of middle- and lowincome countries [77, 78]. Any artificial device (e.g., venous catheter) should carefully be checked for signs of infection. When signs of infection are present, removal of the device represents the key treatment. Infectious signs are frequently insensitive to diagnose infections arising from artificial devices, since infection of internal parts of the device may not cause cutaneous reactions. Therefore, removal of artificial devices should be considered if device-related infection is suspected. Before explanting permanent intravascular (e.g., implanted central venous access) or surgically introduced devices (e.g., hip or knee prosthesis, cardiac pacemaker), other sources of infection need to be safely excluded.

\section{Post-acute interventions}

Post-acute interventions (Table 5) may be postponed until the patient has been resuscitated but should be instituted within $24 \mathrm{~h}$ of recognizing sepsis.

\section{Antimicrobial therapy}

1. Reassess the effectiveness of the antimicrobial regimen regularly (LoE: C).

Background Regular assessment of the patient's response to source control and antimicrobial therapy is essential to promptly recognize inadequate source control. Although no clear time limit has been defined, worsening or ongoing organ dysfunction and persistence of infectious signs (e.g., fever) for more than 48 to $72 \mathrm{~h}$ following initiation of treatment should question the adequacy of sepsis therapy. Common causes of treatment failure are summarized in Table 6. Aside from situations when the patient's condition worsens or fails to improve, empirical antimicrobial therapy should be re-assessed after microbiological results are available. Antimicrobial therapy needs adjustment to pathogen susceptibility. De-escalation of antimicrobial therapy reduces the likelihood of bacterial selection and induction of resistance [79]. If

Table 5 Post-acute interventions to treat septic patients with limited resources

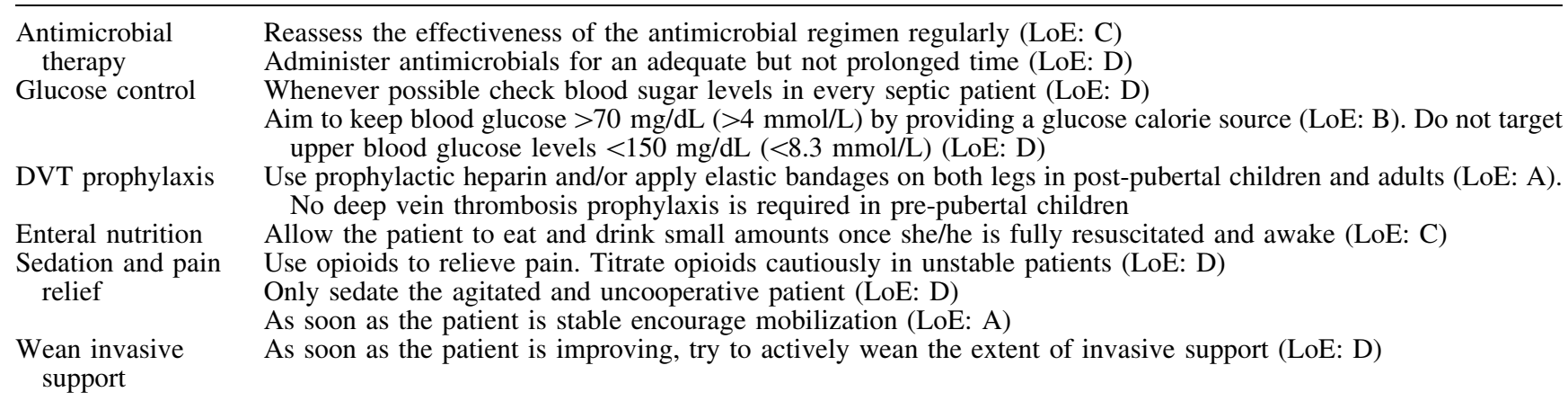

$L o E$ level of evidence, $D V T$ deep venous thrombosis 
Table 6 Common causes for treatment failure in sepsis in resource-poor settings

Inadequate empirical anti-infective therapy ${ }^{\mathrm{a}}$

Missed or insufficient control of the infectious focus

Insufficient supportive therapy (suboptimal fluid resuscitation)

Development of new antimicrobial resistance

Occurence of a new, hospital-acquired infection

Clinical symptoms are due to other diseases than sepsis

a Common reasons for inadequate empirical anti-infective therapy are: wrong group of pathogen targeted (e.g., bacterial instead of protozoic pathogen), administration of antimicrobial with a too narrow spectrum, primary resistance of the pathogen against antimicrobial therapy, use of counterfeit or expired drugs

microbiological cultures remain negative, it is critical to discern whether infection is present but pathogens were not cultivated or a non-infectious disease is present. The sensitivity of microbiological cultures depends on the sampled specimen and is far from $100 \%$, even in highincome countries [75]. Sensitivities of microbiological cultures in resource-limited settings must be assumed to be even lower due to a widespread lack of appropriate inoculation and culture media [80].

2. Administer antimicrobials for an adequate but not prolonged time (LoE: D).

Background The aim of antimicrobial therapy is to administer an adequate anti-infective agent long enough to eradicate causative microbes and short enough to prevent super-infection with microorganisms selected during antimicrobial therapy. Unnecessary antimicrobial therapy, administered for presumed safety reasons, poses a significant threat [81]. The length of antimicrobial treatment must individually be determined based on the type of pathogen cultivated, site of infection, adequacy of source control, treatment response, presence of artificial devices and immune status.

\section{Glucose control}

1. Whenever possible check blood sugar levels in every septic patient (LoE: D).

Background Disturbances of glucose homeostasis often occur in sepsis [82, 83]. Hypoglycemia was observed in $16.3 \%$ of Ugandan patients with sepsis on hospital admission. Hypoglycemia was independently associated with in-hospital mortality. Altered mental state at admission revealed a specificity of $86 \%$ to predict hypoglycemia in septic patients [83]. Certain infectious diseases (e.g., malaria) are associated with an increased risk of hypoglycemia, particularly in children and patients with limited glycogen stores (e.g., malnourished patients or subjects with liver disease) [84]. Considering detrimental effects of even short periods of hypoglycemia [85], blood sugar levels should be measured as early as possible, especially in patients with impaired mental state. If it is not possible to check blood sugar in a patient with impaired mental state at hospital admission, a presumptive diagnosis of hypoglycemia should be made and intravenous glucose administered.

2. Aim to keep blood glucose $>70 \mathrm{mg} / \mathrm{dL}(>4 \mathrm{mmol} / \mathrm{L}$ ) by providing a glucose calorie source (LoE: B). Do not target upper blood glucose levels $<150 \mathrm{mg} / \mathrm{dL}$ $(<8.3 \mathrm{mmol} / \mathrm{L})(\mathrm{LoE}: \mathrm{D})$.

Background Given the harmful effects of hypoglycemia [85], patients without hyperglycemia should receive an oral/enteral or intravenous glucose calorie source to prevent hypoglycemia. In patients presenting with low blood sugar, 30-50 g of glucose must urgently be administered.

Tight glucose control [targeting an upper glucose limit $<150 \mathrm{mg} / \mathrm{dL} \quad(<8.3 \mathrm{mmol} / \mathrm{L})]$ is associated with an increased risk of hypoglycemic events, morbidity and mortality in sepsis and critical illness [34, 85]. In resourcelimited settings, further aspects (e.g., limited availability of resources to measure blood glucose) increase the risk of hypoglycemia when targeting a tight glucose level range. Based on this, we discourage from targeting upper blood glucose levels $<150 \mathrm{mg} / \mathrm{dL}(<8.3 \mathrm{mmol} / \mathrm{L})$.

\section{Deep vein thrombosis prophylaxis}

1. Use prophylactic heparin and/or apply elastic bandages on both legs in adults and post-pubertal children (LoE: A). No deep vein thrombosis prophylaxis is required in pre-pubertal children (LoE: A).

Background Although in many resource-limited settings the prevalence of deep venous thrombosis has been assumed to be too low to justify widespread antithrombotic prophylaxis [86], more recent data point at relevant morbidity and mortality associated with deep venous thrombosis also in middle- and low-income countries [87, 88]. In a post mortem analysis of 989 Nigerian patients, sepsis and immobility $>4$ days were predisposing factors for venous thromboembolism [89]. Routine thromboembolism prophylaxis should be administered to all postpubertal septic patients who have no increased bleeding risk or ongoing hemorrhage [90]. In settings where no heparin is available, either antithrombotic stockings or elastic bandages can be applied [91].

\section{Enteral nutrition}

1. Allow the patient to eat and drink small amounts once she/he is fully resuscitated and awake (LoE: C). 
Background Sepsis disrupts the integrity of the gastrointestinal mucosal barrier and exposes the patient to an increased risk of gastric ulcer formation, particularly when shock, hypoxemia, coagulopathy and corticosteroid therapy are present [92]. Breakdown of the intestinal mucosal barrier can lead to persistent stimulation of the immune system and translocation of bacteria or bacterial components into the bloodstream [93]. Early administration of small amounts of fluids or enteral nutrition through a nasogastric tube improves gastrointestinal mucosal integrity and outcome in highincome settings [94]. At the same time, early enteral nutrition decreases the risk of gastric ulcer formation and upper gastrointestinal hemorrhage [94]. However, early enteral nutrition is not without risks and may cause gastrointestinal ischemia when administered to patients in shock [95]. Particularly in middle- and low-income countries where patients rarely have their airway protected, early enteral nutrition may predispose to gastric regurgitation and pulmonary aspiration [unpublished data, Arjen Dondorp]. Therefore, enteral nutrition should be administered as early as possible, but only after the patient has adequately been resuscitated and is fully awake. In intubated patients, enteral nutrition (e.g., milk supplemented by cooking oil, salt, sugar, soya and a multivitamin tablet) through a nasogastric tube should be initiated after hemodynamic function has stabilized.

Table 7 Suggested therapies to be avoided in the septic patient (level of evidence: D)

DO NOT use hypotonic fluids (e.g., glucose solutions) for fluid
resuscitation
DO NOT use fluid balance as a guide to administer or withhold
further volume loading
DO NOT use high dose steroids (e.g., hydrocortisone $>300 \mathrm{mg} /$ day
or prednisolone $>75 \mathrm{mg} /$ day)

DO NOT use muscle relaxants except for endotracheal intubation and in mechanically ventilated patients with severe respiratory distress

DO NOT use succinylcholine in patients immbolized $>3$ days or with neuromuscular diseases

DO NOT use furosemide unless hypervolemia, hyperkalemia and/or renal acidosis are/is present

DO NOT use dopamine in an attempt to improve renal function

DO NOT use sodium bicarbonate to treat metabolic acidosis arising from tissue hypoperfusion

DO NOT use non-steroidal anti-inflammatory analgesics

DO NOT restrict oxygen because of considerations to reduce respiratory drive

DO NOT diagnose "fever of unknown origin"

DO NOT use insulin if blood sugar cannot be measured regularly

andications for steroids in infectious diseases (Lit mervyn CC 2006): meningitis (dexamethasone $4 \times 10 \mathrm{mg} / \mathrm{day}$ for $48 \mathrm{~h}$, optimally commence before first antibiotic dose, does not seem to be effective in Asian patients), severe pneumocystis jiroveci pneumonia with hypoxemia (prednisolone $2 \times 40 \mathrm{mg} /$ day for 5 days $+1 \times 40 \mathrm{mg} /$ day
Background

Hypotonic fluids only have a little effect on intravascular volume status but carry a high risk of tissue edema, brain edema and dyselectrolytemia

Fluid resuscitation should always be indicated by the patient's condition and the individual response to fluid loading. Significant under-resuscitation may occur

High dose steroids do not change mortality but relevantly increase the risk of hospital-acquired infection, hyperglycemia, gastrointestinal bleeding and/or delirium. Note relevant exceptions $^{\mathrm{a}}$

Muscle relaxants increase the risk of neuromuscular weakness and prolonged paralysis from sepsis

Succinylcholine may cause hyperkalemia resistant to treatment when administered to patients immbolized $>3$ days or with neuromuscular diseases

Furosemide cannot improve kidney function but may even be harmful to the kidney. Treat the patient and not the urine output!

Dopamine cannot prevent renal failure in sepsis but may even cause adverse side effects

Effectiveness of sodium bicarbonate to correct metabolic acidosis is unsure. Although a marker of disease severity, acidosis may have protective effects

Non-steroidal anti-inflammatory analgesics cannot improve sepsis outcome but may impair renal and coagulation function as well as increase the risk of stress ulcer formation

Only few patients with chronic obstructive pulmonary disease have their respiratory drive suppressed by oxygen. The risk of accepting hypoxia in the majority of patients is unacceptably higher than the risk of inducing hypoventilation in a few

"Fever of unknown origin" is a diagnosis by exclusion. Resource limitations usually do not allow for full work-up of patients to make this diagnosis. Always assume and treat infection in the patient in whom fever cannot be explained by other pathologies

If blood sugar is not measured regularly liberal insulin use may result in hypoglycemia with devastating neurological results. Depending on the availability of blood sugar tests adjust the upper glucose limit. If blood sugar can be measured several times a day the optimum blood sugar range would be $70-180 \mathrm{mg} / \mathrm{dL}$ (4-10 $\mathrm{mmol} / \mathrm{L})$

for 5 days $+1 \times 20 \mathrm{mg}$ for 10 days), tuberculous meningitis (dexamethasone $0.3-0.4 \mathrm{mg} / \mathrm{kg} / \mathrm{d}$ tapered over 4 weeks), tuberculous pericarditis (prednisolone $60 \mathrm{mg}$ tapered over 11 weeks), and onchocerciasis (prednisolone $60 \mathrm{mg}$ for 3 days) 


\section{Sedation and pain relief}

1. Use opioids to relieve pain. Titrate opioids cautiously in unstable patients (LoE: D).

Background Opioids are potent analgesics and useful in patients suffering pain. Particularly in unstable patients, they may cause adverse effects (respiratory depression, hypotension, bradycardia, alteration of mental state) and must be used cautiously. This is of particular importance when facilities to secure the airway and provide mechanical ventilation are limited. Opioids should only be administered at diluted concentrations by the intravenous route. Intramuscular injections of large depot dosages may result in unpredictable effects. Septic shock patients typically require lower opioid dosages than hemodynamically stable patients [96]. If opioids are administered a ventilation bag and opioid antagonist should readily be available to treat unexpected respiratory depression.

2. Only sedate the agitated and uncooperative patient (LoE: D).

Background Similar to opioids, sedatives can reduce ventilatory drive, increase the risk of pulmonary aspiration, impair hemodynamic function and alter mental state. Therefore, sedatives should only be administered to agitated and uncooperative patients who cannot be managed by other means. In cases where symptoms of acute delirium prevail, neuroleptic drugs (e.g., haloperidol) are preferred over benzodiazepines [97]. Like opioids, all sedative agents need to be titrated to the patient's response, and emergency equipment be held available. Encourage family members to participate in care to calm the patient.

3. As soon as the patient is stable encourage mobilization (LoE: A).

Background Prolonged bed rest causes numerous unwanted effects, including muscular atrophy, prolonged weakness, respiratory compromise, autonomic dysfunction, hypovolemia, gastrointestinal paralysis, deep venous thrombosis, and delirium [98]. Early mobilization may prevent or counteract these effects and hasten recovery [99].

\section{Wean invasive support}

1. As soon as the patient is improving, try to actively wean invasive support (LoE: D).

Background Every therapy carries risk of adverse effects and may potentially harm. Therapies that are commonly administered and are associated with a high risk of adverse events are invasive procedures [77, 78], use of catecholamines [100], steroids [101] and sedative/ opioid agents [102]. Therapies whose risks outweigh their assumed benefits and should be avoided based on the authors' expert opinion are listed in Table 7. Therefore, it is crucial to actively reduce invasive support as soon as the patient has stabilized. Active but careful reduction of

Table 8 Management of sepsis due to specific causes

Malaria

Puerperal sepsis

Septic patients with HIV/AIDS
Prompt start of parenteral artesunate in adults and children $(2.4 \mathrm{mg} / \mathrm{kg}$ STAT followed by the same dose at $12 \mathrm{~h}, 24 \mathrm{~h}$, and then daily until oral medication can be taken) (LoE: A)

If injectable artesunate is unavailable intramuscular artemether $(3.2 \mathrm{mg} / \mathrm{kg}$ on admission followed by $1.6 \mathrm{mg} / \mathrm{kg}$ daily), artesunate by suppositories $(8-16 \mathrm{mg} / \mathrm{kg}$ at 0 and $12 \mathrm{~h}$ and then daily) or intravenous quinine $(20 \mathrm{mg} / \mathrm{kg}$ loading dose over $4 \mathrm{~h}$ followed by $10 \mathrm{mg} / \mathrm{kg}$ over $4 \mathrm{~h} 8$ hourly until oral medication is possible) can be used (LoE: A)

In children, parenteral antibiotics should be given in addition to antimalarial treatment (LoE: A)

Parenteral antibiotics should be given to adults with slide proven malaria and who present with a clinical syndrome requiring parenteral antibiotics (meningitis/encephalopathy, malnutrition, very severe or severe pneumonia) (LoE: A)

Seizures should be treated with rectal or intravenous diazepam, intravenous lorazepam, paraldehyde or other standard anticonvulsants (LoE: B)

In the absence of shock, fluid management should be performed judiciously and more restrictively than in patients with bacterial sepsis (LoE: B)

In case of severe anemia (e.g., hemoglobin level $<6 \mathrm{~g} / \mathrm{dL}$ ), blood transfusion should be considered (LoE: A) Empirical antibiotic therapy needs to cover Gram-positive, Gram-negative and anaerobic bacteria (LoE: B) Treatment of tuberculosis infection in resource-limited settings is best performed by timely initiation of the combination of isoniazid, rifampicin, pyrazinamide and ethambutol for 2 months followed by isoniazid and rifampicin alone for another 4 months (LoE: A)

Patients with open mycobaterial infections require isolation/cohorting (LoE: A)

In Pneumocystis jiroveci pneumonia, the therapy of choice is trimethoprim/sulfamethoxazole administered for 3 weeks. In patients with hypoxemia, prednisolone ( $40 \mathrm{mg}$ bid for 5 days followed by $40 \mathrm{mg} / \mathrm{day}$ for 5 days and then $20 \mathrm{mg} /$ day for 11 days) should be added (LoE: B)

In malnourished patients, energy supply should be re-started slowly with a stepwise increase of daily caloric intake and avoidance of large amounts of carbohydrates to prevent the re-feeding syndrome (LoE: B)

$L o E$ level of evidence 
therapeutic intensity can reduce length of hospital stay and prevent complications. A prospective study from Thailand revealed that reminding physicians to remove unnecessary urinary catheters reduced the rate of catheterassociated urinary infections [103].

Specific considerations for sepsis management

Specific considerations for the management of septic patients with malaria, puerperal sepsis or HIV/AIDS are summarized in Table 8 and detailed in the Electronic Supplementary Material.

Implementing current recommendations into clinical practice

Effective implementation of guidelines into clinical practice is challenging. Summarizing different recommendations in care bundles has been shown to facilitate implementation of the Surviving Sepsis Campaign guidelines $[8,9]$. Accordingly, we suggest two care bundles in order to implement the presented recommendations on sepsis management in resource-poor settings (Table 9). Although it is yet unclear which guideline implementation strategy is most likely to be efficient [104], several approaches have been successfully applied. Common single interventions include reminders, dissemination of educational materials, audits and feedback. Multifaceted approaches typically involve daily application of checklists, educational outreach, a multidisciplinary approach, as well
Table 9 Suggested care bundles for sepsis management in resource-poor settings

\begin{tabular}{ll}
\hline Acute care bundle & $\begin{array}{l}\text { Oxygen therapy } \\
\text { Fluid resuscitation } \\
\text { Early and adequate antimicrobial therapy } \\
\text { Surgical source control }\end{array}$ \\
Post-acute care bundle & $\begin{array}{l}\text { Re-evaluation of antimicrobial therapy } \\
\text { Deep venous thrombosis prophylaxis } \\
\text { Glucose control } \\
\text { Weaning of invasive support }\end{array}$
\end{tabular}

as a conceptual framework [104]. Dissemination of mobile phone text message reminders to health care workers in Kenya resulted in a sustained improvement of adherence to pediatric malaria guidelines [105].

\section{Endorsements}

The present recommendations for sepsis management in resource-limited settings have been endorsed by the European Society of Intensive Care Medicine, the World Federation of the Pediatric Intensive and Critical Care Societies, the Global Sepsis Alliance, the Federation of Austrian Societies of Intensive Care Medicine, the Ugandan Society of Intensive Care Medicine and the Mongolian Society of Anesthesiology and Intensive Care Medicine.

Conflicts of interest No author has a conflict of interest in regards of drugs or techniques discussed in this manuscript.

\section{References}

1. Adhikari NK, Fowler RA, Bhagwanjee S, Rubenfeld GD (2010) Critical care and the global burden of critical illness in adults. Lancet 376:1339-1346

2. Cheng AC, West TE, Limmathurotsakul D, Peacock SJ (2008) Strategies to reduce mortality from bacterial sepsis in adults in developing countries. PLoS Med 5:e175

3. Black RE, Cousens S, Johnson HL, Lawn JE, Rudan I, Bassani DG, Jha P, Campbell H, Walker CF, Cibulskis R, Eisele T, Liu L, Mathers C, Child Health Epidemiology Reference Group of WHO and UNICEF (2010) Global, regional, and national causes of child mortality in 2008: a systematic analysis. Lancet 375:1969-1987
4. Becker JU, Theodosis C, Jacob ST, Wira CR, Groce NE (2009) Surviving sepsis in low-income and middleincome countries: new directions for care and research. Lancet Infect Dis 9:577-582

5. World Health Organization. The Global Burden of Disease: 2004 update. http://www.who.int/ healthinfo/global_burden_disease/ 2004_report_update/en/index.html. Accessed April 2011

6. Dellinger RP, Carlet JM, Masur H, Gerlach H, Calandra T, Cohen J, GeaBanacloche J, Keh D, Marshall JC, Parker MM, Ramsay G, Zimmerman JL, Vincent JL, Levy MM (2004) Surviving sepsis campaign guidelines for management of severe sepsis and septic shock. Intensive Care Med 30:536-555
7. Dellinger RP, Levy MM, Carlet JM, Bion J, Parker MM, Jaeschke R, Reinhart K, Angus DC, Brun-Buisson C, Beale R, Calandra T, Dhainaut JF, Gerlach H, Harvey M, Marini JJ, Marshall J, Ranieri M, Ramsay G, Sevransky J, Thompson BT, Townsend S, Vender JS, Zimmerman JL, Vincent JL (2008) Surviving sepsis campaign: international guidelines for management of severe sepsis and septic shock. Intensive Care Med 34:17-60 
8. Levy MM, Dellinger RP, Townsend SR, Linde-Zwirble WT, Marshall JC, Bion J, Schorr C, Artigas A, Ramsay G, Beale R, Parker MM, Gerlach H, Reinhart K, Silva E, Harvey M, Regan S, Angus DC (2010) The surviving sepsis campaign: results of an international guideline-based performance improvement program targeting severe sepsis. Intensive Care Med 36:222-231

9. Ferrer R, Artigas A, Levy MM, Blanco J, González-Díaz G, GarnachoMontero J, Ibáñez J, Palencia E, Quintana M, de la Torre-Prados MV, Edusepsis Study Group (2008) Improvement in process of care and outcome after a multicenter severe sepsis educational program in Spain. JAMA 299:2294-2303

10. Kissoon N, Carcillo J, Espinosa V, Argent A, Devictor D, Madden M, Singhi S, van der Voort E, Latour J, Global Sepsis Initiative Vanguard Center Contributors (2010) World federation of pediatric intensive care and critical care societies: the global sepsis initiative. Pediatr Crit Care Med epub ahead of print

11. Brierley J, Carcillo JA, Choong K, Cornell T, Decaen A, Deymann A, Doctor A, Davis A, Duff J, Dugas MA, Duncan A, Evans B, Feldman J, Felmet K, Fisher G, Frankel L, Jeffries H, Greenwald B, Gutierrez J, Hall M, Han YY, Hanson J, Hazelzet J,

Herman L, Kiff J, Kissoon N, Kon A, Irazuzta J, Lin J, Lorts A, Mariscalco M, Mehta R, Nadel S, Nguyen T, Nicholson C, Peters M, OkhuysenCawley R, Poulton T, Relves M, Rodriguez A, Rozenfeld R, Schnitzler E, Shanley T, Kache S, Skippen P, Torres A, von Dessauer B, Weingarten J, Yeh T, Zaritsky A, Stojadinovic B, Zimmeran J, Zuckerberg A (2009)

Clinical practice parameters for hemodynamic support of pediatric and neonatal septic shock: 2007 update for the American College of Critical Care Medicine. Crit Care Med 33:666-688

12. Baelani I, Jochberger S, Laimer T, Otieno D, Kabutu J, Wilson I, Baker T, Dünser MW (2011) Availability of critical care resources to treat patients with severe sepsis or septic shock in Africa: a self-reported, continent-wide survey of anaesthesia providers. Crit Care 15:R10

13. Bataar O, Lundeg G, Tsenddorj G, Jochberger S, Grander W, Baelani I, Wilson I, Baker T, Dünser MW, Helfen Berührt Study Team (2010) Nationwide survey on resource availability for implementing current sepsis guidelines in Mongolia. Bull World Health Organ 88:839-846
14. Kissoon N (2011) Out of Africa-a mother's journey. Pediatr Crit Care Med 12:73-79

15. Santhanam I, Kissoon N, Kamath SR, Ranjit S, Ramesh J, Shankar J (2009) GAP between knowledge and skills for the implementation of the ACCM/ PALS septic shock guidelines in India: is the bridge too far? Indian J Crit Care Med 13:54-58

16. Dünser MW, Baelani I, Ganbold L (2006) A review and analysis of intensive care medicine in the least developed countries. Crit Care Med 34:1234-1242

17. Dünser MW, Takala J, Ulmer H, Mayr VD, Luckner G, Jochberger S, Daudel F, Lepper P, Hasibeder WR, Jakob SM (2009) Arterial blood pressure during early sepsis and outcome. Intensive Care Med 35:1225-1233

18. Howell MD, Donnino M, Clardy P, Talmor D, Shapiro NI (2007) Occult hypoperfusion and mortality in patients with suspected infection. Intensive Care Med 33:1892-1899

19. Pamba A, Maitland K (2004) Capillary refill: prognostic value in Kenyan children. Arch Dis Child 89:950-955

20. Zanotti Cavazzoni SL, Dellinger RP (2006) Hemodynamic optimization of sepsis-induced tissue hypoperfusion. Crit Care 10(Suppl 3):S2

21. Zanotti-Cavazzoni SL, Guglielmi M, Parrillo JE, Walker T, Dellinger RP, Hollenberg SM (2009) Fluid resuscitation influences cardiovascular performance and mortality in a murine model of sepsis. Intensive Care Med 35:748-754

22. Mock C, Visser L, Denno D, Maier R (1995) Aggressive fluid resuscitation and broad spectrum antibiotics decrease mortality from typhoid ileal perforation. Trop Doct 25:115-117

23. Jacob ST, Moore CC, Banura P, Pinkerton R, Meya D, Opendi P, Reynolds SJ, Kenya-Mugisha N, Mayanja-Kizza H, Scheld WM, Promoting Resource-Limited Interventions for Sepsis Management in Uganda (PRISM-U) Study Group (2009) Severe sepsis in two Ugandan hospitals: a prospective observational study of management and outcomes in a predominantly HIV-1 infected population. PLoS One 4:e7782

24. Molyneux E, Ahmad S, Robertson A (2006) Improved triage and emergency care for children reduces inpatient mortality in a resourceconstrained setting. Bull World Health Organ 84:314-319
25. Wills BA, Nguyen MD, Ha TL, Dong TH, Tran TN, Le TT, Tran VD, Nguyen TH, Nguyen VC, Stepniewska K, White NJ, Farrar JJ (2005) Comparison of three fluid solutions for resuscitation in dengue shock syndrome. N Engl J Med 353:877-989

26. Ranjit S, Kissoon N, Jayakumar I (2005) Aggressive management of dengue shock syndrome may decrease mortality rate: a suggested protocol. Pediatr Crit Care Med 6:412-419

27. Maitland K, Kiguli S, Opoka RO, Engoru C, Olupot-Olupot P, Akech SO, Nyeko R, Mtove G, Reyburn H, Lang T, Brent B, Evans JA, Tibenderena JK, Crawley J, Russell EC, Levin M, Babiker AG, Gibb DM (2011) Mortality after fluid bolus in African children with severe infection. N Engl J Med May 26 (epub ahead of print)

28. Upadhyay M, Singhi S, Murlidharan J, Kaur N, Majumdar S (2005) Randomized evaluation of fluid resuscitation with crystalloid (saline) and colloid (polymer from degraded gelatin in saline) in pediatric septic shock. Indian Pediatr 42:223-231

29. CHOICE Study Group (2001) Multicenter, randomized, double-blind clinical trial to evaluate the efficacy and safety of a reduced osmolarity oral rehydration salts solution in children with acute watery diarrhea. Pediatrics 107:613-618

30. Perel P, Roberts I (2011) Colloids versus crystalloids for fluid resuscitation in critically ill patients. Cochrane Database Syst Rev 3:CD000567

31. Akech S, Ledermann H, Maitland $\mathrm{K}$ (2010) Choice of fluids for resuscitation in children with severe infection and shock: systematic review. BMJ 341:c4416

32. Perel P, Roberts I (2007) Colloids versus crystalloids for fluid resuscitation in critically ill patients. Cochrane Database Syst Rev 4:CD000567

33. Karila C, Brunet-Langot D, Labbez F, Jacqmarcq O, Ponvert C, Paupe J, Scheinmann P, de Blic J (2005) Anaphylaxis during anesthesia: results of a 12-year survey at a French pediatric center. Allergy 60:828-834

34. Brunkhorst FM, Engel C, Bloos F, Meier-Hellmann A, Ragaller M, Weiler N, Moerer O, Gruendling M, Oppert M, Grond S, Olthoff D, Jaschinski U, John S, Rossaint R, Welte T, Schaefer M, Kern P, Kuhnt E, Kiehntopf M, Hartog C, Natanson C, Loeffler M, Reinhart K, German Competence Network Sepsis (SepNet) (2008) Intensive insulin therapy and pentastarch resuscitation in severe sepsis. N Engl J Med 358:125-139 
35. Annane D, Vignon P, Renault A, Bollaert PE, Charpentier C, Martin C, Troché G, Ricard JD, Nitenberg G, Papazian L, Azoulay E, Bellissant E, CATS Study Group (2007)

Norepinephrine plus dobutamine versus epinephrine alone for management of septic shock: a randomised trial. Lancet 370:676-684

36. Myburgh JA, Higgins A, Jovanovska A, Lipman J, Ramakrishnan N, Santamaria J, CAT Study Investigators (2008) A comparison of epinephrine and norepinephrine in critically ill patients. Intensive Care Med 34:2226-2234

37. De Backer D, Biston P, Devriendt J, Madl C, Chochrad D, Aldecoa C, Brasseur A, Defrance P, Gottignies P, Vincent JL, SOAPII Investigators (2010) Comparison of dopamine and norepinephrine in the treatment of shock. N Engl J Med 362:779-789

38. Day NP, Phu NH, Bethell DP, Mai NT, Chau TT, Hien TT, White NJ (1996) The effects of dopamine and adrenaline infusions on acid-base balance and systemic haemodynamics in severe infection. Lancet 348:219-223

39. Tourneux P, Rakza T, Abazine A, Krim G, Storme L (2008) Noradrenaline for management of septic shock refractory to fluid loading and dopamine or dobutamine in fullterm newborn infants. Acta Paediatr 97:177-180

40. Deedat AM, Wilson IH, Watters DA (1990) Central venous pressure monitoring for the critically ill in Zambia. Trop Doct 20:74-76

41. Chen JL, O'Shea M (1998) Extravasation injury associated with low-dose dopamine. Ann Pharmacother 32:545-548

42. Marik PE, Pastores SM, Annane D, Meduri GU, Sprung CL, Arlt W, Keh D, Briegel J, Beishuizen A, Dimopoulou I, Tsagarakis S, Singer M, Chrousos GP, Zaloga G, Bokhari F, Vogeser M, American College of Critical Care Medicine (2008)

Recommendations for the diagnosis and management of corticosteroid insufficiency in critically ill adult patients: consensus statements from an international task force by the American College of Critical Care Medicine. Crit Care Med 36:1937-1949

43. Moran JL, Graham PL, Rockliff S, Bersten AD (2010) Updating the evidence for the role of corticosteroids in severe sepsis and septic shock: a Bayesian meta-analytic perspective. Crit Care 14:R134
44. Valoor HT, Singhi S, Jayashree M (2009) Low-dose hydrocortisone in pediatric septic shock: an exploratory study in a third world setting. Pediatr Crit Care Med 10:121-125

45. Bernard GR, Luce JM, Sprung CL, Rinaldo JE, Tate RM, Sibbald WJ, Kariman K, Higgins S, Bradley R, Metz CA (1987) High-dose corticosteroids in patients with the adult respiratory distress syndrome. N Engl J Med 317:1565-1570

46. Hotchkiss RS, Karl IE (2003) The pathophysiology and treatment of sepsis. N Engl J Med 348:138-150

47. Wandi F, Peel D, Duke T (2006) Hypoxaemia among children in rural hospitals in Papua New Guinea: epidemiology and resource availability - a study to support a national oxygen programme. Ann Trop Paediatr 26:277-284

48. Walker IA, Merry AF, Wilson IH, McHugh GA, O'Sullivan E, Thoms GM, Nuevo F, Whitaker DK, GO Project Teams (2009) Global oximetry: an international anaesthesia quality improvement project. Anaesthesia 64:1051-1060

49. Duke T, Subhi R, Peel D, Frey B (2009) Pulse oximetry: technology to reduce child mortality in developing countries. Ann Trop Paediatr 29:165-175

50. Duke T, Wandi F, Jonathan M, Matai S, Kaupa M, Saavu M, Subhi R, Peel D (2008) Improved oxygen systems for childhood pneumonia: a multihospital effectiveness study in Papua New Guinea. Lancet 372:1328-1333

51. Drakulovic MB, Torres A, Bauer TT, Nicolas JM, Nogué S, Ferrer M (1999) Supine body position as a risk factor for nosocomial pneumonia in mechanically ventilated patients: a randomised trial. Lancet 354:1851-1858

52. Torres A, Serra-Batlles J, Ros E, Piera C, Puig de la Bellacasa J, Cobos A, Lomeña F, Rodríguez-Roisin R (1992) Pulmonary aspiration of gastric contents in patients receiving mechanical ventilation: the effect of body position. Ann Intern Med 116:540-543

53. Tantipong $\mathrm{H}$, Morkchareonpong $\mathrm{C}$, Jaiyindee S, Thamlikitkul V (2008) Randomized controlled trial and metaanalysis of oral decontamination with $2 \%$ chlorhexidine solution for the prevention of ventilator-associated pneumonia. Infect Control Hosp Epidemiol 29:131-136

54. Nava S, Hill N (2009) Non-invasive ventilation in acute respiratory failure. Lancet 374:250-259
55. Hussain SF, Haqqee R, Iqbal J (2004) Non-invasive ventilation in the management of acute respiratory failure in Pakistan. Trop Doct 34:238-239

56. George IA, John G, John P, Peter JV, Christopher S (2007) An evaluation of the role of noninvasive positive pressure ventilation in the management of acute respiratory failure in a developing country. Indian J Med Sci 61:495-504

57. Cam BV, Tuan DT, Fonsmark L, Poulsen A, Tien NM, Tuan HM, Heegaard ED (2002) Randomized comparison of oxygen mask treatment vs. nasal continuous positive airway pressure in dengue shock syndrome with acute respiratory failure. J Trop Pediatr 48:335-339

58. Santhanam I, Sangareddi S, Venkataraman S, Kissoon N, Thiruvengadamudayan V, Kasthuri RK (2008) A prospective randomized controlled study of two fluid regimens in the initial management of septic shock in the emergency department. Pediatr Emerg Care 24:647-655

59. Amato MB, Barbas CS, Medeiros DM, Magaldi RB, Schettino GP, LorenziFilho G, Kairalla RA, Deheinzelin D, Munoz C, Oliveira R, Takagaki TY, Carvalho CR (1998) Effect of a protective-ventilation strategy on mortality in the acute respiratory distress syndrome. N Engl J Med 338:347-354

60. Randolph AG (2009) Management of acute lung injury and acute respiratory distress syndrome in children. Crit Care Med 37:2448-2454

61. The Acute Respiratory Distress Syndrome Network (2000) Ventilation with lower tidal volumes as compared with traditional tidal volumes for acute lung injury and the acute respiratory distress syndrome. N Engl J Med 342:1301-1308

62. Putensen C, Mutz NJ, PutensenHimmer G, Zinserling J (1999) Spontaneous breathing during ventilatory support improves ventilation-perfusion distributions in patients with acute respiratory distress syndrome. Am J Respir Crit Care Med 159:1241-1248

63. Han YY, Carcillo JA, Dragotta MA, Bills DM, Watson RS, Westerman ME, Orr RA (2003) Early reversal of pediatric-neonatal septic shock by community physicians is associated with improved outcome. Pediatrics 112:793-799 
64. Rivers E, Nguyen B, Havstad S, Ressler J, Muzzin A, Knoblich B, Peterson E, Tomlanovich M, Early Goal-Directed Therapy Collaborative Group (2001) Early goal-directed therapy in the treatment of severe sepsis and septic shock. N Engl J Med 345:1368-1377

65. Oliveira CF, Nogueira de Sá FR, Oliveira DS, Gottschald AF, Moura JD, Shibata AR, Troster EJ, Vaz FA, Carcillo JA (2008) Time- and fluidsensitive resuscitation for hemodynamic support of children in septic shock: barriers to the implementation of the American College of Critical Care Medicine/ Pediatric Advanced Life Support Guidelines in a pediatric intensive care unit in a developing world. Pediatr Emerg Care 24:810-815

66. Kumar A, Roberts D, Wood KE, Light B, Parrillo JE, Sharma S, Suppes R, Feinstein D, Zanotti S, Taiberg L, Gurka D, Kumar A, Cheang M (2006) Duration of hypotension before initiation of effective antimicrobial therapy is the critical determinant of survival in human septic shock. Crit Care Med 34:1589-1596

67. Kumar A, Ellis P, Arabi Y, Roberts D, Light B, Parrillo JE, Dodek P, Wood G, Kumar A, Simon D, Peters C, Ahsan M, Chateau D, Cooperative Antimicrobial Therapy of Septic Shock Database Research Group (2009) Initiation of inappropriate antimicrobial therapy results in a fivefold reduction of survival in human septic shock. Chest 136:1237-1248

68. Gaieski DF, Mikkelsen ME, Band RA, Pines JM, Massone R, Furia FF, Shofer FS, Goyal M (2010) Impact of time to antibiotics on survival in patients with severe sepsis or septic shock in whom early goal-directed therapy was initiated in the emergency department. Crit Care Med 38:1045-1053

69. Gomes MF, Faiz MA, Gyapong JO, Warsame M, Agbenyega T, Babiker A, Baiden F, Yunus EB, Binka F, Clerk C, Folb P, Hassan R, Hossain MA, Kimbute O, Kitua A, Krishna S, Makasi C, Mensah N, Mrango Z, Olliaro P, Peto R, Peto TJ, Rahman MR, Ribeiro I, Samad R, White NJ, Study 13 Research Group (2009) Prereferral rectal artesunate to prevent death and disability in severe malaria: a placebo-controlled trial. Lancet 373:557-566
70. Mandomando I, Sigaúque B, Morais L, Espasa M, Vallès X, Sacarlal J, Macete E, Aide P, Quintò L, Nhampossa T, Machevo S, Bassat Q, Menéndez C, Ruiz J, Roca A, Alonso PL (2010) Antimicrobial drug resistance trends of bacteremia isolates in a rural hospital in southern Mozambique. Am J Trop Med Hyg 83:152-157

71. Kamolratanakul P, Dhanamun B, Thaithong S (1992) Human behavior in relation to selection of malaria treatment. Southeast Asian J Trop Med Public Health 23:189-194

72. Thamlikitkul V (1998) Antibiotic dispensing by drug store personnel in Bangkok, Thailand. J Antimicrob Chemother 21:125-131

73. Asghar R, Banajeh S, Egas J, Hibberd P, Iqbal I, Katep-Bwalya M, Kundi Z, Law P, MacLeod W, Maulen-Radovan I, Mino G, Saha S, Sempertegui F, Simon J, Santosham M, Singhi S, Thea DM, Qazi S, Severe Pneumonia Evaluation Antimicrobial Research Study Group (2008) Chloramphenicol versus ampicillin plus gentamicin for community acquired very severe pneumonia among children aged 2-59 months in low resource settings: multicentre randomised controlled trial (SPEAR study). BMJ 336:80-84

74. Taccone FS, Laterre PF, Dugernier T, Spapen H, Delattre I, Wittebole X, De Backer D, Layeux B, Wallemacq P, Vincent JL, Jacobs F (2010) Insufficient $\beta$-lactam concentrations in the early phase of severe sepsis and septic shock. Crit Care 14:R126

75. Shafazand S, Weinacker AB (2002) Blood cultures in the critical care unit: improving utilization and yield. Chest 122:1727-1736

76. Nickerson EK, Wuthiekanun V, Wongsuvan G, Limmathurosakul D, Srisamang P, Mahavanakul W, Thaipadungpanit J, Shah KR, Arayawichanont A, Amornchai P, Thanwisai A, Day NP, Peacock S (2009) Factors predicting and reducing mortality in patients with invasive Staphylococcus aureus disease in a developing country. PLoS One 4:e6512

77. Rosenthal VD, Maki DG, Mehta A, Alvarez-Moreno C, Leblebicioglu H, Higuera F, Cuellar LE, Madani N, Mitrev Z, Dueñas L, Navoa-Ng JA, Garcell HG, Raka L, Hidalgo RF, Medeiros EA, Kanj SS, Abubakar S, Nercelles P, Pratesi RD, International Nosocomial Infection Control Consortium Members (2008) International Nosocomial Infection Control Consortium report, data summary for 2002-2007, issued January 2008. Am J Infect Control 36:627-637
78. Rosenthal VD, Maki DG, Rodrigues C, Alvarez-Moreno C, Leblebicioglu H, Sobreyra-Oropeza M, Berba R, Madani N, Medeiros EA, Cuéllar LE, Mitrev Z, Dueñas L, Guanche-Garcell H, Mapp T, Kanj SS, FernándezHidalgo R, International Nosocomial Infection Control Consortium Investigators (2010) Impact of International Nosocomial Infection Control Consortium (INICC) strategy on central line-associated bloodstream infection rates in the intensive care units of 15 developing countries. Infect Control Hosp Epidemiol 31:1264-1272

79. Masterton RG (2011) Antibiotic deescalation. Crit Care Clin 27:149-162

80. Katawa G, Kpotsra A, Karou DS, Eklou M, Tayi KE, de Souza C (2011) Contribution to the establishment of quality assurance in five medical microbiology departments in Togo. Bull Soc Pathol Exot 104:20-24

81. Mentzelopoulos SD, Pratikaki M, Platsouka E, Kraniotaki H, Zervakis D, Koutsoukou A, Nanas S, Paniara O, Roussos C, Giamarellos-Bourboulis E, Routsi C, Zakynthinos SG (2007) Prolonged use of carbapenems and colistin predisposes to ventilatorassociated pneumonia by pandrugresistant Pseudomonas aeruginosa. Intensive Care Med 33:1524-1532

82. Rattanataweeboon P, Vilaichone W, Vannasaeng S (2009) Stress hyperglycemia in patients with sepsis. J Med Assoc Thai 92(Suppl 2):S88S94

83. Ssekitoleko R, Jacob ST, Banura P, Pinkerton R, Meya DB, Reynolds SJ, Kenya-Mugisha N, Mayanja-Kizza R, Bhagani S, Scheld WM, Moore CC (2011) Hypoglycemia at admission is associated with inhospital mortality in Ugandan patients with severe sepsis. Crit Care Med 39:2271-2276

84. Ogetii GN, Akech S, Jemutai J, Boga M, Kivaya E, Fegan G, Maitland K (2010) Hypoglycaemia in severe malaria, clinical associations and relationship to quinine dosage. BMC Infect Dis 10:334

85. Finfer S, Chittock DR, Su SY, Blair D, Foster D, Dhingra V, Bellomo R, Cook D, Dodek P, Henderson WR, Hébert PC, Heritier S, Heyland DK, McArthur C, McDonald E, Mitchell I, Myburgh JA, Norton R, Potter J, Robinson BG, Ronco JJ, NICESUGAR Study Investigators (2009) Intensive versus conventional glucose control in critically ill patients. N Engl J Med 360:1283-1297

86. Osime U, Lawrie J, Lawrie H (1976) Post-operative deep vein thrombosis incidence in Nigerians. Niger Med J 6:26-28 
87. Colin JF, Rottcher KH, Dhali DP (1975) Letter: venous thrombosis in Africans. Lancet 1:408

88. Lee AD, Stephen E, Agarwal S, Premkumar P (2009) Venous thromboembolism in India. Eur J Vasc Endovasc Surg 37:482-485

89. Sotunmbi PT, Idowu AT, Akang EE, Aken'Ova YA (2006) Prevalence of venous thromboembolism at postmortem in an African population: a cause for concern. Afr J Med Med Sci 35:345-348

90. Samama MM, Cohen AT, Darmon JY, Desjardins L, Eldor A, Janbon C, Leizorovicz A, Nguyen H, Olsson CG, Turpie AG, Weisslinger N (1999) A comparison of enoxaparin with placebo for the prevention of venous thromboembolism in acutely ill medical patients. Prophylaxis in Medical Patients with Enoxaparin Study Group. N Engl J Med 341:793-800

91. Amaragiri SV, Lees TA (2000) Elastic compression stockings for prevention of deep vein thrombosis. Cochrane Database Syst Rev 3:CD001484

92. Cook DJ, Fuller HD, Guyatt GH, Marshall JC, Leasa D, Hall R, Winton TL, Rutledge F, Todd TJ, Roy P (1994) Risk factors for gastrointestinal bleeding in critically ill patients. Canadian Critical Care Trials Group. N Engl J Med 330:377-381

93. Temmesfeld-Wollbrück B, Szalay A, Mayer K, Olschewski H, Seeger W, Grimminger F (1998) Abnormalities of gastric mucosal oxygenation in septic shock: partial responsiveness to dopexamine. Am J Respir Crit Care Med 157:1586-1592
94. Doig GS, Heighes PT, Simpson F, Sweetman EA, Davies AR (2009) Early enteral nutrition, provided within $24 \mathrm{~h}$ of injury or intensive care unit admission, significantly reduces mortality in critically ill patients: a meta-analysis of randomised controlled trials. Intensive Care Med 35:2018-2027

95. Lawlor DK, Inculet RI, Malthaner RA (1998) Small-bowel necrosis associated with jejunal tube feeding. Can J Surg 41:459-462

96. Berkenstadt H, Segal E, Mayan H, Almog S, Rotenberg M, Perel A, Ezra D (1999) The pharmacokinetics of morphine and lidocaine in critically ill patients. Intensive Care Med 25:110-112

97. Milbrandt EB, Kersten A, Kong L, Weissfeld LA, Clermont G, Fink MP, Angus DC (2005) Haloperidol use is associated with lower hospital mortality in mechanically ventilated patients. Crit Care Med 33:226-229

98. Brower RG (2009) Consequences of bed rest. Crit Care Med 37(10 Suppl):S422-S428

99. Schweickert WD, Pohlman MC, Pohlman AS, Nigos C, Pawlik AJ, Esbrook CL, Spears L, Miller M, Franczyk M, Deprizio D, Schmidt GA, Bowman A, Barr R, McCallister KE, Hall JB, Kress JP (2009) Early physical and occupational therapy in mechanically ventilated, critically ill patients: a randomised controlled trial. Lancet 373:1874-1882

100. Dünser MW, Ruokonen E, Pettilä V, Ulmer $\mathrm{H}$, Torgersen $\mathrm{C}$, Schmittinger CA, Jakob S, Takala J (2009) Association of arterial blood pressure and vasopressor load with septic shock mortality: a post hoc analysis of a multicenter trial. Crit Care 13:R181
101. Sprung CL, Annane D, Keh D, Moreno R, Singer M, Freivogel K, Weiss YG, Benbenishty J, Kalenka A, Forst H, Laterre PF, Reinhart K, Cuthbertson BH, Payen D, Briegel J, CORTICUS Study Group (2008) Hydrocortisone therapy for patients with septic shock. N Engl J Med 358:111-124

102. Strøm T, Martinussen T, Toft P (2010) A protocol of no sedation for critically ill patients receiving mechanical ventilation: a randomised trial. Lancet 375:475-480

103. Apisarnthanarak A, Thongphubeth K, Sirinvaravong S, Kitkangvan D, Yuekyen C, Warachan B, Warren DK, Fraser VJ (2007) Effectiveness of multifaceted hospitalwide quality improvement programs featuring an intervention to remove unnecessary urinary catheters at a tertiary care center in Thailand. Infect Control Hosp Epidemiol 28:791-798

104. Grimshaw JM, Thomas RE, MacLennan G, Fraser C, Ramsay CR, Vale L, Whitty P, Eccles MP, Matowe L, Shirran L, Wensing M, Dijkstra R, Donaldson C (2004) Effectiveness and efficiency of guideline dissemination and implementation strategies. Health Technol Assess 8:1-72

105. Zurovac D, Sudoi RK, Akhwale WS, Ndiritu M, Hamer DH, Rowe AK, Snow RW (2011) The effect of mobile phone text-message reminders on Kenyan health workers' adherence to malaria treatment guidelines: a cluster randomized trial. Lancet 378:795-803 